\title{
Real time phase encoded MR for assessment of acute variability of central pulse wave velocity
}

\author{
Nicholas Gaddum*, Tobias Schaeffter, Philipp B Beerbaum \\ From 15th Annual SCMR Scientific Sessions \\ Orlando, FL, USA. 2-5 February 2012
}

\section{Background}

The variability of pulse wave velocity (PWV) with changing arterial wall stress may reflect the degree of aortic stiffness independent of arterial pressure. We implemented a real-time MR flow technique so as to be able to assess acute changes in PWV due to affected arterial blood and/or intra thoracic pressure. The aim of this study was to assess the accuracy of rapid PWV assessment using the real time MR technique.

\section{Methods}

We developed a novel real-time MR dual-slice protocol (RT-DS), with interleaved through-plane acquisitions of projected left to right velocity to rapidly measure central pulse wave velocity (PWV). An automated in-house post-processing tool measures mean velocity pulse wave transit time and aortic length, permitting PWV assessment from projected image data. In a pulsatile flow phantom, RT-DS-derived PWV was validated against pressure-wire-PWV (gold-standard) and in-plane 2D phase-contrast MRI (PC-MRI). In 17 healthy adult volunteer scans (mean age, $32 \pm 7$; mean arterial blood pressure $89 \pm 7 \mathrm{mmHg}$ ), agreement of PWV by RT-DS was compared with in-plane PC-MRI.

\section{Results}

Excellent correlation of assessed PWV between pressure wire $(6.35 \pm 0.18 \mathrm{~m} / \mathrm{s})$ and both RT-DS and PC-MRI scans were observed, $(6.20 \pm 0.61 \mathrm{~m} / \mathrm{s}, \mathrm{P}=0.70$, and 6.33 $\pm 0.70 \mathrm{~m} / \mathrm{s}, \mathrm{P}=0.96$, respectively), in vitro. Volunteer velocity profiles with located wave 'foot' locations using both MR scanning protocols are shown in the figure below for comparison. In the volunteer cohort, the RT-DS and PCMRI scans showed a correlation of $0.9,(\mathrm{r} 2=0.25, \mathrm{P}$ > 0.04). RT-DS derived PWV was lower than standard PC-

Imaging Sciences, King's College London, London, UK
MRI (mean difference, $-0.46 \pm 0.78 \mathrm{~m} / \mathrm{s}$ ). Inter-scan variability of PWV by RT-DS was $0.41 \pm 0.32 \mathrm{~m} / \mathrm{s}$. Regional PWV between ascending/descending and descending/abdominal aorta lacked reproducibility.

\section{Conclusions}

Real-time dual-slice projection phase-contrast MRIS is accurate and reproducible to assess the aortic PWV. The method has potential to detect acute the variability of PWV in response to variation in arterial blood and/or intra thoracic pressure as a measure of arterial stiffness.

\section{Funding}

Medical Research Council, UK.

Published: 1 February 2012

doi:10.1186/1532-429X-14-S1-W51

Cite this article as: Gaddum et al:: Real time phase encoded MR for assessment of acute variability of central pulse wave velocity. Journal of Cardiovascular Magnetic Resonance 2012 14(Suppl 1):W51.

Submit your next manuscript to BioMed Central and take full advantage of:

- Convenient online submission

- Thorough peer review

- No space constraints or color figure charges

- Immediate publication on acceptance

- Inclusion in PubMed, CAS, Scopus and Google Scholar

- Research which is freely available for redistribution
(C) 2012 Gaddum et al; licensee BioMed Central Ltd. This is an open access article distributed under the terms of the Creative Commons Attribution License (http://creativecommons.org/licenses/by/2.0), which permits unrestricted use, distribution, and reproduction in any medium, provided the original work is properly cited. 


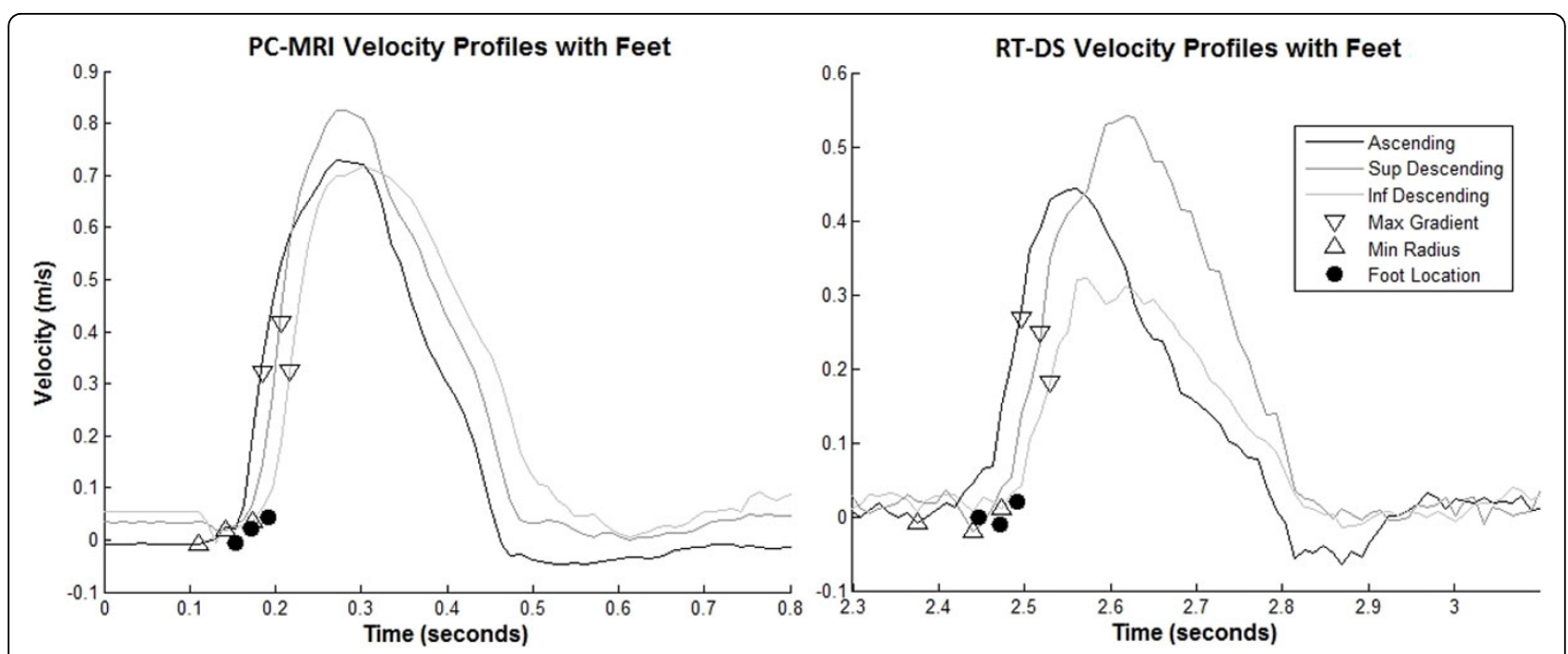

Figure 1 PC-MRI (left) and RT-DS (right) velocity profiles with located wave 'feet' from a volunteer scan 